\title{
Wild Boar: A Threat to Europe's Pig Industry
}

\author{
José Luis Benedito ${ }^{1}$, Joaquín Hernández ${ }^{1}$, José Miguel Chapel ${ }^{1}$, Cristina \\ Castillo $^{1 *}$ and Rodrigo Muiñ̃o ${ }^{2}$ \\ ${ }^{1}$ Animal Pathology Department, Spain. \\ ${ }^{2}$ Veterinary Practitioner, Spain
}

ISSN: 2637-7659

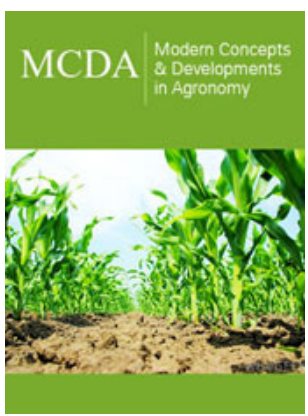

*Corresponding author: Cristina Castillo, Department of Animal Pathology, College of Veterinary Medicine, Spain

Submission: 侮 May 16, 2019

Published: 海 May 21, 2019

Volume 4 - Issue 2

How to cite this article: José $L$ B, Joaquín H, José Miguel C, Cristina C, Rodrigo M. Wild Boar: A Threat to Europe's Pig Industry. Mod Concep Dev Agrono.4(3). MCDA.000586.2019.

DOI: 10.31031/MCDA.2019.04.000586

Copyright@ Cristina Castillo, This article is distributed under the terms of the Creative Commons Attribution 4.0 International License, which permits unrestricted use and redistribution provided that the original author and source are credited.

\begin{abstract}
Since 2014 the African Swine Fever (ASF), is advancing through wild boar to Spain from Eastern European countries (Lithuania, Latvia, Estonia and Poland, borders of Austria, the Czech Republic, Slovakia, Poland, Ukraine, Romania, Serbia and northern Hungary). Officially, according with the European Commission this disease was eradicated in France (1974), Mainland Italy (1993), Belgium (1985)., Netherlands (1986), Spain (1994) and Portugal (1999). But the threaten has emerged again. From the point of view of Animal Health, an alert has been issued at European level prohibiting exports of this type of animals, whether live or dead, especially their by-products. Recently, at the end of February 2019, wild boars affected by this disease were found at frontiers of Belgium, Luxembourg and France. Although the disease is not transmissible to humans, we want to make an appeal here, because the transmission of the disease to any pig farm would cause a health alarm, having to empty the farm, with the enormous economic loss that this would entail for the farm. In this article we analyze what the African Swine Pest is, the role played by the overpopulation of wild boar in its distribution and the preventive measures to be adopted.
\end{abstract}

\section{Introduction}

\section{The wild boar problem}

Wild boar (Sus scrofa) populations suffered strong demographic declines until the mid20th century in some areas of Europe (e.g. Denmark, Sweden and Italy), but are now expanding at an accelerated rate due to a number of contributing factors such as relatively low numbers of predators like the wolf or fox, climate change, intensification of crop production, reforestation of agricultural areas, the depopulation of the countryside and the lack of cleanliness of mountains, reduction of hunting pressure, and intentional releases for hunting purposes [1]. In the last few months, the media reports have not stopped accusing the wild boar of being the cause of a multitude of traffic accidents, putting them at the core of society's rejection; it is also true that they destroy the fields of cereals (specially corn fields) and vegetables, even destroying the football fields of the nearby urban centers. There's also some news in the press of attacks on people of wild boar; and their appearance and walks through cities and towns, creating social alarm by their aggressiveness. But we have to remember that the wild boar is an animal that has a capacity of adaptation above the average of the other animals. In addition to be an omnivorous animal can opt for a vegetarian or carnivorous diet (also eat carrion) thereby facilitating their subsistence. This is accompanied by his agility, which makes it easier for him to enter and stay in forests that are inaccessible to human beings. On the other hand, his extraordinary senses of hearing and olfaction (sight is not their strength), makes it difficult to control their population only through hunting. In the search for food they use their good smell and the ability to root (in fact, they are considered the best "diggers" of nature).

\section{African swine fever}

African Swine Fever (ASF) is a highly contagious disease that is caused by a virus of the family Asfarviridae, genus asfivirus, existing strains that can cause acute or hyper-acute episodes, with mortality and morbidity levels close to $100 \%$, although other strains cause sub-acute or even chronic clinical symptoms with lower mortality. It originates hemorrhagic lesions in the skin and internal organs due to vascular lesions, but contrary to Classical Swine Fever (CSF), this disease does not normally present nervous symptoms [2]. However, it is impossible to differentiate these two viral diseases by means of symptomatology, and in the case of suspicion, it is necessary to take samples from the suspected animal for laboratorial diagnosis in a reference center for both diseases. In the case of Spain, this center is located at 
Madrid. Classical swine fever was first recognized in North America in 1830, where was known as swine cholera, and shortly thereafter in Europe. Eradicated from most of the northwestern hemisphere, apart from a very large outbreak that occurred in the Netherlands in 1997 and smaller outbreaks in European countries, including the UK and Germany (data available from the World Organization for Animal Health (OIE) databases and the World Animal Health Information Database (WAHID), www.oie.org.), it remains prevalent in Eastern Europe, Asia and South America.

The history of ASF as a pig disease in Africa probably dates back to the first-time domestic pigs were introduced into an area where wild boars were infected. The first recorded outbreaks were detected on farms belonging to European farmers in Kenya in 1914, leading to studies that found it to be a disease other than classical swine fever. Although only one serotype of African swine fever virus is recognized, multiple genotypes have been reported, implying that the evolution of African swine fever virus has been a long process [3]. The introduction of ASF virus genotype I in Portugal in 1957, probably from Angola, was quickly eradicated, but a second introduction in 1960 led to its subsequent spread to the Iberian Peninsula, as well as to several other European countries, the Caribbean (Cuba, Dominican Republic and Haiti) and Brazil. In the 1990s, it had been eradicated from all those countries, with the exception of the Italian island of Sardinia, where it has been established since 1978. In 2007, classical swine fever virus genotype II was diagnosed in the Republic of Georgia, followed by its spread to Armenia, Azerbaijan and Russia, where it is already well established and continues to spread [4,5]. Within the European Union (EU), strict controls have been established on the import of animals, animal products and animal by-products, in order to mitigate the effects of the epidemic caused by this disease and with devastating effects at the livestock level. However, illegal or uncontrolled imports of pork products, either accidentally by tourists returning from endemic countries ("sandwich theory", which occurs when someone carries pork products (sausages, mortadella, ham, etc. on a sandwich and throws the debris in the street), or, more importantly, by intentionally smuggling meat products for personal or commercial use, represents a continuing threat. To mitigate the risk of infection of domestic pigs through exposure to food waste feed, EU countries have to comply with the Animal By-products Regulation. The absence of this type of regulation may have led to the introduction of ASF in the Caucasus region [6]. In the U.S. and Canada, pork production has increased in recent years. In 2018 the European Union and United States were second and third in the list, after China, with over 150 and 73.2 million heads respectively (see https://www.statista.com/ statistics/263964/number-of-pigs-in-selected-countries.). The main threat to pig farms in these two countries is the introduction of ASF-infected pig products into the food waste from aircraft and ships arriving from endemic countries. As in Europe, the strict rules governing waste disposal by the United States Department of Agriculture (USDA) reduce the risk of ASF introduction. In addition, effective surveillance, monitoring along supply and commodity chains and strict control and prevention policies allow early detection of outbreaks of African swine fever and the slaughter of all infected animals, combined with compensation by affected stakeholders.

\section{Preventive measures}

At the beginning of the year, the Spanish Ministry of Agriculture published a renewed National Wildlife Health Surveillance Plan (2019), which are rules that must be taken into account in order to know how to act with wild species [7]. The main initiatives of the EU on ASF are based on:
A. Preparedness,
B. Regionalization,
C. Scientific advice,
D. Urgent intervention,
E. Audits,
F. International cooperation,
G. Public awareness,
H. Financial support and
I. Research [8].

It seems vital that the awareness of the sector should be full, because on the other hand, if boars spread ASF, the pig sector in the affected area may disappear and, of course, the boars may also be affected (as the virus does not distinguish between the two species), with mortality rates of up to $100 \%$. One example is the implementation of border controls against ASF in Estonia, Latvia, Lithuania and Poland and border controls against ASF in Latvia and Estonia. Since January 2019 the European Union's executive body is supporting Poland's slaughter of wild boars as a way of protecting farm pigs and meat production from the deadly ASF. But it is not the only country, Germany killed over 800,000 wild boars last year as a precaution against the advance of this disease. Another strategy that seems very useful, in the mid-term, is the management of wild boar populations in the EU, not only through hunting, in order to ensure the survival of the species itself. This action must be taken in matters such as the regulation of the area (monitoring the rubbish dumps that those who come to eat), prohibiting supplementary feeding by citizens or the regulation of crops, adapted to the particular situation of each area of the EU Member State. Awareness and communication campaigns are also essential, highlighting the danger of transmission of ASF by wild boars to all the agents involved (producers, hunters, consumers, tourists) and the general public, in order to minimize the accidental entry of the virus across borders and, above all, on routes between EU states. But we also want to go further and point out the certain irresponsibility of those owners who have Vietnamese pigs as pets that do not vaccinate them or that when they grow up are abandoned in the mountains, crossing with wild boars, transmitting the disease. It is also important to encourage the development of slaughterhouses for hunting species by the government institutions, increasing the veterinary control of meat. Society must demand from national and local institutions 
more economic funds so that each area has control of this disease. And finally, any person who finds a corpse of wild boar in the forest or in the field, which is not shot, must report it to the competent authority for health inspection, and send the samples of the corpse to the reference laboratory if there is any clinical doubt.

\section{Conclusion}

As the EU Agriculture Commissioner Phil Hogan said in 2018 "We need to take a very serious look now at the spread of this disease and to take it more seriously perhaps in some member states than we have been in relation to bio-security measures". This opinion should apply to all countries producing and exporting pig meat.

\section{References}

1. Iacolina L, Pertoldi C, Amills M, Kusza S, Megens HJ, et al. (2018) Hotspots of recent hybridization between pigs and wild boars in Europe. Sci Rep 8(1): 17372 .
2. Radostits OM, Gay CC, Hinchcliff KW, Constable PD (2006) Veterinary Medicine. A textbook of the diseases of cattle, horses, sheep, pigs and goats. ( $10^{\text {th }}$ edn.), Saunders, New York, USA.

3. Mary Louise Penrith ML (2013) History of 'swine fever' in southern Africa. Journal of the South African Veterinary Association 84(1): a1106.

4. Gogin A, Gerasimov V, Malagolovkin A, Kolbasov D (2013) African swine fever in the North Caucasus region and the Russian Federation in years 2007-2012. Virus Res 173(1): 198-203.

5. Oganesyan AS, Petrova ON, Korennoy FI, Bardina NS, Gogin AE, et al. (2013) African swine fever in the Russian Federation: Spatio-temporal analysis and epidemiological overview. Virus Res 173(1): 204-211.

6. Costard S, Wieland B, de Glanville W, Jori F, Rowlands R, et al. (2009) African swine fever: how can global spread be prevented? Philos Trans R Soc B Biol. 364(1530): 2683-2696.

7. Spanish Ministry of Agriculture, Fisheries and Food (2019) National Wildlife Health Surveillance Plan.

8. European Commision (2018) ASF and the legislative framework: the management of disease eradication through awareness and cooperation.

For possible submissions Click below: 